\title{
Improvement of Quality of Life in Patients with Concomitant Allergic Asthma and Atopic Dermatitis: One Year Follow-up of OMalizumab Therapy
}

\author{
P. Velling ${ }^{1 *}$, D. Skowasch²*, S. Pabst ${ }^{2}$, E. Jansen ${ }^{2}$, I. Tuleta ${ }^{2}$, C. Grohé ${ }^{1}$ \\ ${ }^{1}$ Lungenklinik Berlin-Buch, Germany, \\ ${ }^{2}$ Department of Internal Medicine II - Pneumology, University of Bonn, Germany
}

\begin{abstract}
Objective: Anti $\mathrm{IgE}$ treatment with omalizumab is efficacious in the treatment of patients suffering from allergic asthma, improving asthma control and improving quality of life. Furthermore, this approach could be beneficial for patients with concomitant atopic dermatitis. We assessed quality of life and asthma control in atopic patients with allergic asthma and concomitant atopic dermatitis versus those with asthma and without atopic dermatitis treated with omalizumab. Methods: A total of 22 patients with severe allergic asthma were treated with omalizumab for 12 months. 13 patients with allergic asthma without concomitant atopic dermatitis ( $\mathrm{IgE} 212 \pm 224 \mathrm{IU} / \mathrm{ml}$ ) and 9 patients with concomitant allergic asthma and atopic dermatitis $(\mathrm{IgE} 3,528 \pm 2,723 \mathrm{IU} / \mathrm{ml})$ were included. Asthma-related quality of life (AQLQ), atopic dermatitis related quality of life (DLQI), and asthma-related treatment were compared between both groups at baseline and after initiating omalizumab treatment. Results: DLQI was significantly in favor of omalizumab after 2 months in the atopic dermatitis/asthma group $(\mathrm{P}=0.01)$; AQLQ was improved after 6 months in the asthma group $(\mathrm{P}=0.01)$, while no change was seen in AQLQ in the atopic dermatitis/asthma group $(\mathrm{P}=0.12)$. Omalizumab controlled oral corticosteroid use more effective $(\mathrm{P}<0.01)$ in patients with asthma and atopic dermatitis (in $9 / 9$ cases) compared to patients with asthma alone (9/13). Baseline $\operatorname{IgE}$ as well as other factors do not predict response to omalizumab. Conclusions: Omalizumab is effective in improving atopic dermatitis-related quality of life scores and modulates oral corticosteroid use in patients with concomitant asthma and atopic dermatitis in a positive fashion.
\end{abstract}

Key words: allergic asthma, anti-IgE, atopic dermatitis, omalizumab, quality of life

\section{INTRODUCTION}

Atopic dermatitis is a chronic cutaneous inflammatory disease in childhood that often persists into adult-

\footnotetext{
* P. Velling and D. Skowasch contributed equally to these
} studies hood [2]. It is characterized by pruritic skin lesions and frequently associated with allergic asthma disease, and atopic diathesis, or both. The syndrome of atopy may include allergic rhino conjunctivitis, allergic asthma, and atopic dermatitis; most cases of moderate to severe atopic dermatitis do not respond adequate to any single therapeutic modality and many management strategies based on systemic or local corticosteroids are limited by their systemic toxicities. Currently, we do not have effective pharmacological monotherapies with acceptable safety profiles to control the symptoms of this disease in the long run.

Omalizumab is an anti-immunoglobulin $\mathrm{E}(\mathrm{IgE})$ monoclonal antibody for use in IgE-mediated allergic asthma. The efficacy of omalizumab has been extensively evaluated in several clinical studies in patients with predominantly severe persistent allergic asthma $[3,5,6,11]$. Omalizumab has proven effective over a wide range of outcome measures including asthma exacerbation rates, total emergency visit rates, and quality of life (QoL). Both diseases - asthma and atopic dermatitis - are associated with elevated serum IgE levels, that are strongly increased in patients with atopic dermatitis. Indeed, omalizumab has been experimentally used in various atopic skin diseases including atopic dermatitis with high $\mathrm{IgE}$ levels. Efficacy of omalizumab in atopic skin diseases is heterogeneous and ranges from very good efficacy to no effect at all in case reports and small studies $[7,8,9,13,14]$. However, no data exist on the evaluation of omalizumab treatment in patients with both atopic dermatitis and asthma.

The aim of the present study was to evaluate the efficacy and safety of omalizumab in patients with concomitant asthma and atopic dermatitis versus those with asthma alone. In particular, we were interested in changes of quality of life and asthma control.

\section{Methods}

In a prospective monocenter investigation we assessed a series of 22 atopic patients with omalizumab therapy for 12 months starting between July 2006 and October 2008. Inclusion criteria for all patients were identical to that of the INNOVATE study [6, 12] - except serum IgE levels $(\geq 30$ to $\leq 700 \mathrm{IU} / \mathrm{ml})$. Inclusion cri- 
teria were very strict in order to enrol the most severe patients with persistent allergic asthma (12-75 years): Positive skin prick test to $\geq 1$ perennial aeroallergen, to which they were likely to be exposed during the study, severe persistent asthma requiring regular treatment with $>1000 \mu \mathrm{g} /$ day beclomethason dipropionate or equivalent and long-acting $\beta 2$-agonist (Global Initiative for Asthma (GINA) step 4 treatment), forced expiratory volume in $1 \mathrm{~s}$ (FEV1) $\geq 40$ to $<80 \%$ of predicted normal value and continuing asthma symptoms, FEV1 reversibility $\geq 12 \%$ from baseline within $30 \mathrm{~min}$ of inhaled (up to $400 \mu \mathrm{g}$ ) or nebulized (up to $5 \mathrm{mg}$ ) salbutamol, despite high-dose ICS and LABA use at least two asthma exacerbations requiring systemic corticosteroids, or one severe exacerbation [peak expiratory flow (PEF)/FEV1 $<60 \%$ of personal best, requiring systemic corticosteroids] resulting in hospitalization or emergency room treatment, in the past 12 months. Thirteen patients with allergic asthma served as controls, and 9 patients with concomitant allergic asthma and atopic dermatitis were included. Patients with allergic asthma alone had a mean FEV1 of $71 \%$ of predicted, patients with concomitant atopic dermatitis of $76 \%$ (Table 1 ).

Whereas total serum IgE levels were $>30$ to $<700$ $\mathrm{IU} / \mathrm{ml}$ (mean $212 \pm 224 \mathrm{IU} / \mathrm{ml}$ ) in patients with asthma alone, all patients with concomitant atopic dermatitis displayed total serum $\mathrm{IgE}$ values above 700 $\mathrm{IU} / \mathrm{ml}$ (mean 3,528 $\pm 2,723 \mathrm{IU} / \mathrm{ml}$ ). The dose of omalizumab (Xolair, Novartis, Nürnberg, Germany) was dependent on body weight and serum IgE levels and was administered every 2 or 4 weeks, as described $[3,6]$. Patients with concomitant atopic dermatitis were treated regardless of $\operatorname{IgE}$ values with $150 \mathrm{mg}$ s.c. in 14 day intervals based on the observation of previ-

Table 1. Patient characteristics, asthma-related quality of life (AQLQ), atopic dermatitis related quality of life (DLQI), and asthma-related treatment at baseline and after 6 and 12 months omalizumab therapy. OCS, oral corticosteroids, ICS, inhaled corticosteroids.

\begin{tabular}{lccr}
\hline & Asthma & $\begin{array}{c}\text { Asthma }+ \\
\text { atopic dermatitis }\end{array}$ & P value \\
$\mathrm{n}$ & 13 & 9 & \\
\hline Age (Years) & $47.5 \pm 14.8$ & $38.1 \pm 11.3$ & 0.127 \\
Sex / female) & $10 / 1377 \%$ & $6 / 967 \%$ & 0.394 \\
IgE & $212 \pm 224$ & $3528 \pm 2723$ & $<0.001$ \\
FEV1 & $71.5 \pm 10,7$ & $76.2 \pm 7,4$ & 0.350 \\
Weight in kg & $82.3 \pm 22.0$ & $76.3 \pm 16.1$ & 0.472 \\
Omalizumab dosage & & & \\
(mg/2 weeks) & $213 \pm 86$ & $233 \pm 109$ & 0.654 \\
OCS baseline & $12 / 13$ & $7 / 9$ & 0.394 \\
OCS 6 month & $4 / 13$ & $0 / 9$ & 0.003 \\
OCS 12 month & $4 / 13$ & $0 / 9$ & 0.003 \\
AQLQ baseline & $102 \pm 40$ & $143 \pm 44$ & 0.041 \\
AQLQ 6 month & $148 \pm 48$ & $175 \pm 40$ & 0.041 \\
AQLQ 12 month & $152 \pm 45$ & $170 \pm 42$ & 0.04 \\
DLQI baseline & & $19 \pm 10$ & \\
DLQI 6 month & & $7 \pm 8$ & \\
DLQI 12 moth & & $6 \pm 6$ & \\
\hline
\end{tabular}

ous work [1, 10]. Omalizumab dosage was increased up to a improvement of dermatological status; dosage did not exceed the maximal two week-dosage of 450 mg s.c. Asthma-related quality of life (AQLQ), atopic dermatitis related quality of life (DLQI) [4], and treatment with oral steroids were compared between both groups at baseline and 1, 2, 3, 6 and 12 months after initiating omalizumab treatment. Adverse events were recorded at each treatment visit. 5 additional patients with asthma alone were excluded from study analysis due to anaphylactic reaction after first omalizumab injection $(n=1)$ or discontinuation of therapy due to unsatisfactory therapeutic effect on asthma despite correct dosage within the first six months $(n=4)$.

\section{STATISTICAL ANALYSIS}

Probability was calculated with the students t-test; P values of $<0.05$ were considered to be statistically significant. All studies have been carried out according to the Helsinki declaration of good clinical practice.

\section{RESULTS}

Patient characteristics, such as age, gender, and medication did not differ between patients with asthma (n $=13$ ) and patients with concomitant asthma and atopic dermatitis $(n=9)$ and are presented in Table 1 . All patients were receiving inhaled corticosteroids ( $>1000 \mu \mathrm{g} /$ day beclomethason dipropionate or equivalent) and long-acting $\beta 2$-agonists (fixed combination of fluticason/salmeterol or budesonid/formeterol), $12 / 13$ of patients with asthma and $7 / 9$ of patients with asthma/atopic dermatitis received additional maintenance oral corticosteroid at baseline. Consistently, patients with asthma and atopic dermatitis showed significantly higher serum $\operatorname{IgE}$ values than patients with asthma alone $(3,528 \pm 2,723 \mathrm{IU} / \mathrm{ml}$ vs. 212 $\pm 224 \mathrm{IU} / \mathrm{ml}, \mathrm{P}<0.001)$. Of note, there was no significant difference between both groups regarding the omalizumab dosage.

AQLQ was improved for the total collective ( $\mathrm{P}=$ $0.01)$ and in the asthma alone group after 6 months $(P$ $=0.01$ ), while no change was seen in AQLQ in the atopic dermatitis/asthma group $(\mathrm{P}=0.12)$ (Fig. 1). There were no significant changes at earlier time points. DLQI was significantly in favor of omalizum$\mathrm{ab}$ after 2 months in the asthma/atopic dermatitis group $(P=0.01)$; this effect was seen until 12 months (Fig. 2). Overall improvements in DLQI indices as well as in minimizing topic corticosteroids in skin therapy were found in all patients with asthma/atopic dermatitis. During treatment, both patient groups lowered their use of oral corticosteroids: All (9/9) patients with asthma/atopic dermatitis discontinued oral corticosteroid use, whereas $9 / 13$ patients with asthma alone stopped this therapy.

Baseline IgE, age, body weight, FEV1 and dosage of omalizumab do not predict response to omalizum$\mathrm{ab}$.

Overall, 4 of the 22 patients having received 12 months omalizumab $(18 \%)$ experienced at least one adverse effect: headache $(\mathrm{n}=1)$, local reaction at point of injection $(n=4)$ and nausea $(n=1)$. 

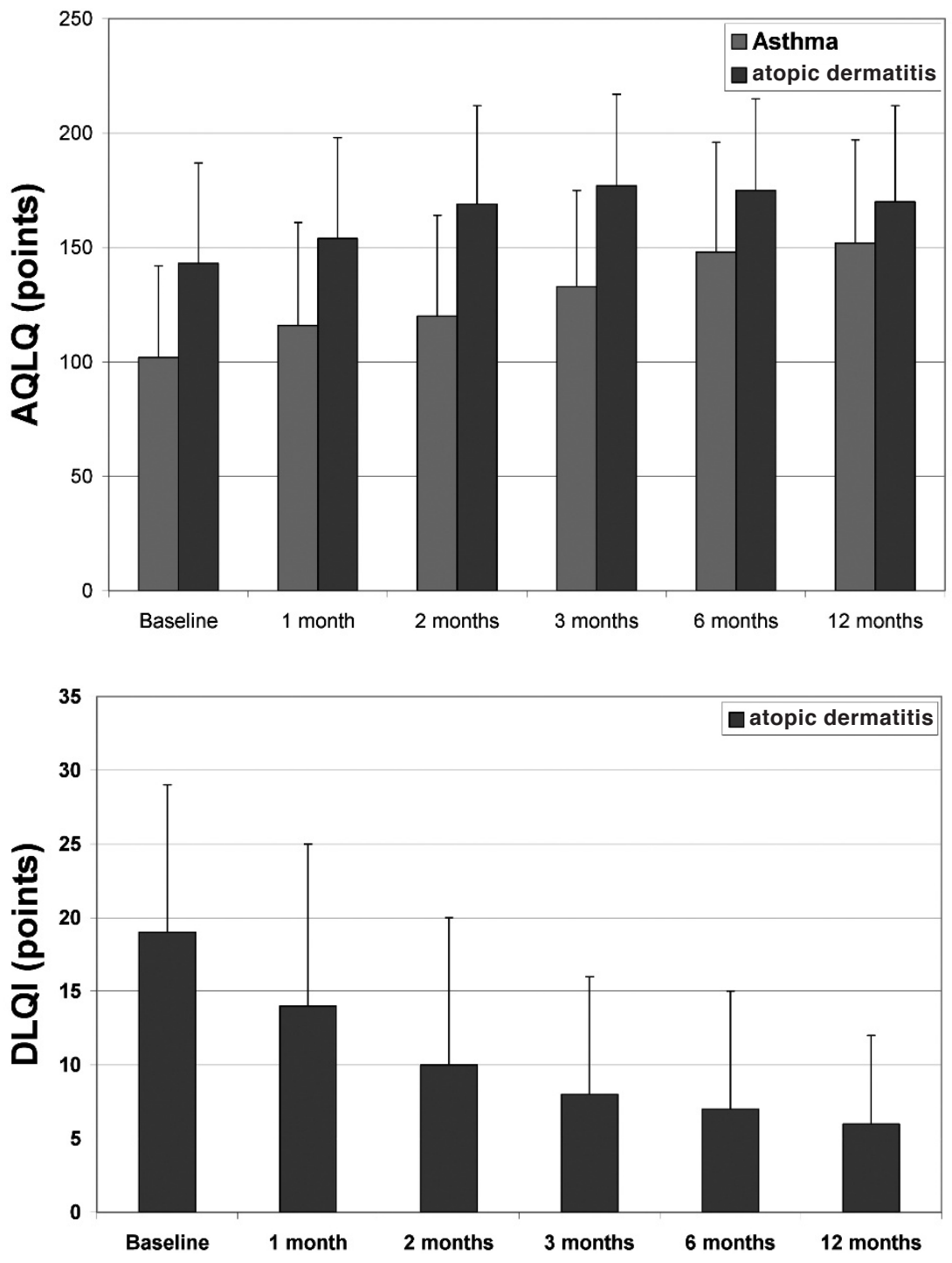

Fig. 1. Time course of AQLQ for patients with asthma alone (red) and concomitant atopic dermatitis and asthma (blue). AQLQ was improved in the asthma alone group after 6 months omalizumab treatment $(\mathrm{P}<0.05$ : 2 months, 3 months, 6 months and 12 months vs. baseline), while no significant change was seen in AQLQ in the atopic dermatitis/asthma group.

\section{Discussion}

The present study is the first designed to evaluate the efficacy of omalizumab on quality of life (QoL) in patients with concomitant asthma and atopic dermatitis. Omalizumab is effective in improving atopic dermatitis-related QoL scores and modulates oral corticosteroid treatment. All patients had severe persistent asthma as defined by Global Initiative for Asthma (GINA) guidelines [12]. Omalizumab was used as an add-on treatment to standard management. Indeed, improvement in asthma QoL in the groups was similar and comparable to other reports with omalizumab [3, 6]. In addition, in the comorbid population suffering from atopic dermatitis and asthma, treatment with omalizumab resulted in significant improvements of atopic dermatitis-related QoL and in reduction of use of oral corticosteroids. Choice of the long-term observational interval ( $>12$ months) was based on the possibility and variability of placebo-induced clinical improvement in atopic dermatitis. This phenomenon was described in the first three months of observation period in up to $40 \%$ of the cases after initiation of a new treatment option [1]. Of interest, changes in atopic dermatitis-related QoL were seen 2 months af- ter initiating omalizumab treatment, whereas improved asthma QoL reached significance only after 6 months.

Of note, the present improvement of QoL scores in patients with concomitant atopic dermatitis and asthma was observed with low-dose anti $\operatorname{IgE}$ treatment $(233 \pm 109 \mathrm{mg} / 2$ weeks $)$ and, therefore, was in a much lower dosage than required for the complete removal of $\mathrm{IgE}$ from the circulation, as recently also described by Lim and Belloni [1, 10]. They had observed free IgE remained basically stable over the omalizumab treatment period and suggested other, molecular effects such as a switch to reduced $\operatorname{IgE}$ mRNA production responsible for skin improvement $[1,10]$. One may speculate, that those patients with lower IgE levels would show a better QoL improvement, however, this is not shown by the present data. Indeed, mean $\mathrm{IgE}$ level 3,528 $\pm 2,723 \mathrm{IU} / \mathrm{ml}$ in the present study is even higher than in previous studies, for example $1,521 \mathrm{IU} / \mathrm{ml}$ in the work of Sheinkopf and colleagues [13].

There are several limitations of this single-center project with a small study collective that was designed as a pilot study, not as a randomized trial. The concept that underlies this study was the screening of the impact on quality of life brought on by omalizumab de- 
scription in patients with atopic disease, as seen in "daily practice".

In conclusion, this study extends previously published reports on omalizumab in atopic dermatitis [1, $10,13]$ by integrating patients with concomitant asthma and atopic dermatitis and found that omalizumab is significantly efficacious in improving disease-related QoL when added to standard asthma and atopic dermatitis therapies. Further placebo-controlled studies in this patient collective are warranted.

\section{REFERENCES}

1. Belloni B, Ziai M, Lim A, Lemercier B, Sbornik M, Weidinger $\mathrm{S}$ et al Low-dose anti-IgE in patients with atopic eczema with high serum IgE levels. J Allergy Clin Immunol 2008 Nov;120(5):1223-1225.

2. Bieber T. Atopic dermatitis. N Engl J Med 2008 Apr;358(14):1483-94.

3. Bousquet J, Cabreba P, Berkman N. Buhl R, Holgate S, Wenzel S et al. The effect of treatment with omalizumab, an anti-IgE antibody, on asthma exacerbations and emergency medical visits in patients with severe persistent asthma. Allergy 2005 Mar;60 (3):302-308.

4. Finlay AY, Khan GK. Dermatology life quality Index (DLQI): A simple practical measure for routine clinical use. Clinical and Experimental Dermatology 1994 May;19 (3):210-216.

5. Holgate S, Buhl R, Bousquet J, Smith N, Panahloo Z, Jimenez P. The use of omalizumab in the treatment of severe allergic asthma: A clinical experience update. Resp Med 2009 Aug;103(8):1098-1113.

6. Humbert M, Beasly R, Ayres J, Slavin R, Hebert J, Bousquet $\mathrm{J}$ et al. Benefits of omalizumab as add-on therapy in patients with severe persistent asthma who are inadequately controlled despite best available therapy (GINA 2002 step 4 treatment): INNOVATE. Allergy 2005 Mar;60(3):309-316.

7. Incorvaia C, Pravettoni C, Mauro M, Yacoub MR, Tarantini F, Riario-Sforza GG. Effectiveness of omalizumab in a patient with severe asthma and atopic dermatitis. Monaldi Arch Chest Dis 2008 Jun;69(2):78-80.
8. Krathen RA, Hsu S. Failure of Omalizumab for treatment of severe adult atopic dermatitis. J Am Acad Dermatol 2005 Aug;35(2):338-340.

9. Lane JE, Cheyney JM, Lane TN, Kent DE, Cohen DJ. Treatment of recalcitrant atopic dermatitis with Omalizumab. J Am Acad Dermatol 2006 Jan;54(1):68-72.

10. Lim A, Luderschmidt S, Weidinger A, Schnopp C, Ring J, Hein R, Ollert M, Mempel M. The IgE repertoire in PBMCs of atopic patients is characterized by individual reaarangements without variable region of the heavy immunoglobulin chain bias. J Allergy Clin Immunol 2007 Sep;120(3):696-706,

11. Molimard M, de Blay F, Didier A, Le Gros V. Effectiveness of omalizumab (Xolair) in the first patients treated in real-life practice in France. Respir Med. 2008 Jan; 102(1):71-76

12. National Institutes of Health. Global Initiative for Asthma. Global Strategy for Asthma Management and Prevention 2007. Available from: http:/ /www.ginaasthma.com

13. Sheinkopf LE, Rafi AW, Do LAT, Katz RM, Klaustermeyer WB. Efficacy of Omalizumab in the treatment of atopic dermatitis: A pilot study. Allergy and Asthma Proceedings 2008 Sep-Oct;29(5):530-537.

14. Vigo PG, Girgis KR, Pfuetze BL, Critchlow ME, Fisher J, Hussain I. Efficacy of anti-IgE therapy in patients with atopic dermatitis. J Am Acad Dermatol 2006 Jul;5 (1): 168-170.

Received: November 29, 2010 / Accepted: December 2, 2010

\author{
Addresss for correspondence: \\ Peter Velling, MD \\ Lungenklinik Berlin-Buch \\ Lindenberger Weg 27 \\ 13125 Berlin \\ Tel.: 030-94802112 \\ Fax: 030-94802250 \\ Email: Velling@elk-berlin.de
}

